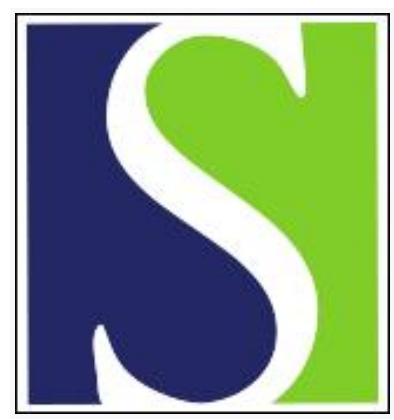

Scand J Work Environ Health 2014;40(3):323-330

https://doi.org/10.5271/sjweh.3399

Published online: 12 Nov 2013, Issue date: 01 May 2014

Risk of cryptorchidism among sons of horticultural workers and farmers in Denmark

by Jørgensen $K T$, Jensen MS, Toft GV, Larsen AD, Bonde JP, Hougaard KS

Previous studies suggest that maternal horticulture work increase cryptorchidism risk among sons. This cohort study found a slightly increased risk among sons of maternal horticultural workers and farmers. However, similar findings for paternal horticultural workers, and no association for women likely working in the first trimester suggest that this relationship is not directly caused by maternal occupational exposure to pesticides.

Affiliation: Department of Occupational and Environmental Medicine, Bispebjerg Hospital, DK-2400 Copenhagen NV, Denmark. Kristian.tore.joergensen@regionh.dk

Key terms: cohort study; cryptorchidism; Denmark; farmer; farming; horticultural worker; horticulture; occupational exposure; orchiopexy; pesticide

This article in PubMed: www.ncbi.nlm.nih.gov/pubmed/24220013 


\title{
Risk of cryptorchidism among sons of horticultural workers and farmers in Denmark
}

\author{
by Kristian Tore Jørgensen, MSc, PhD, , 2 Morten Søndergaard Jensen, MD, PhD, ${ }^{3}$ Gunnar Vase Toft, \\ MSc, PhD, ${ }^{4}$ Ann Dyreborg Larsen, MSc, ${ }^{1,4}$ Jens Peter Bonde, MD, PhD, DMSc, ${ }^{2}$ Karin Sørig Hougaard, \\ MSc, $P h D^{1}$
}

\begin{abstract}
Jørgensen KT, Jensen MS, Toft GV, Larsen AD, Bonde JP, Hougaard KS. Risk of cryptorchidism among sons of horticultural workers and farmers in Denmark. Scand J Work Environ Health. 2014;40(3):323-330. doi:10.5271/ sjweh.3399
\end{abstract}

Objectives Previous studies indicate an increased risk of cryptorchidism, incomplete testicular descent, among sons of women working with pesticides. This study assessed the risk of cryptorchidism among boys of parents employed as horticultural workers and farmers using nationwide registers on occupation and cryptorchidism.

Methods The cohort consisted of $>600000$ boys born in Denmark from 1980-2007 with a parent in employment during pregnancy. These boys were followed for cryptorchidism from 1980-2009 comparing risks among sons of horticultural workers and farmers with sons of parents in other occupations. Hazard ratios (HR) and $95 \%$ confidence intervals $(95 \% \mathrm{CI}$ ) were estimated using Cox regression adjusting for parental age, birth years, parity, and geographical region.

Results Sons of maternal farmers were at increased risk of cryptorchidism (157 cases; HR 1.31, 95\% CI 1.12-1.53) compared to boys of mothers in other occupations (15 511 cases). Paternal occupation as farmer was unrelated to the risk among sons. Maternal occupation as a horticultural worker was associated with a nonsignificantly increased risk ( 72 cases; HR 1.20, 95\% CI 0.95-1.52). A similar association was found for paternal horticultural workers. Sons of maternal farmers or horticultural workers who likely worked in the first trimester were not at increased risk of cryptorchidism.

Conclusions This nationwide cohort study found a slightly increased risk of cryptorchidism in sons of maternal horticultural workers and farmers. However, subgroup analyses indicated similar findings for paternal horticultural workers, and no association for women likely working in the first trimester. The main findings should therefore be interpreted with caution.

Key terms cohort study; farming; horticulture; occupational exposure; orchiopexy; pesticide.

Farming and horticulture constitute two main occupations with possible exposure of employees to pesticides. In Denmark, about $80 \%$ of female horticultural workers use pesticides in work while about $20 \%$ of female farmers spray pesticides (1). For male farmers, pesticide exposure is considerably more common $(2,3)$. Chemicals applied in farming and horticulture have various biologic actions and toxicities and especially some pesticides have known estrogenic or antiandrogenic effects $(4,5)$. Adverse effects on genital development have been demonstrated in various animal male fetuses for instance for mixtures of epoxiconazole, mancozeb, prochloraz, tebuconazole, and procymidone (6-9). However, the long-term consequences of pesticide exposure in humans are generally unknown. Concern has especially focused on pregnant workers regarding possible adverse effects on normal fetal development and, considering the antiandrogenic effects, malformations of the male reproductive organs in particular. Cryptorchidism is characterized by incomplete testicular descent and is a common malformation seen in about $2 \%$ of boys at three months of age (10-12). Previous studies from

1 The National Research Centre for the Working Environment, Copenhagen, Denmark.

2 Department of Occupational and Environmental Medicine, Bispebjerg Hospital, Copenhagen University Hospital, Copenhagen, Denmark.

3 Perinatal Epidemiology Research Unit, Department of Pediatrics, Aarhus University Hospital, Skejby, Denmark.

4 Department of Occupational Medicine, Aarhus University Hospital, Aarhus, Denmark.

Correspondence to: Kristian Tore Jørgensen, Department of Occupational and Environmental Medicine, Bispebjerg Hospital, DK-2400 Copenhagen NV, Denmark. [E-mail: kristian.tore.joergensen@regionh.dk] 
Denmark have indicated an increased risk of cryptorchidism among sons of women (i) working in horticulture during pregnancy and (ii) with high pesticide levels in breast milk. In contrast, no associations have been found for maternal farmers or fathers working in horticulture or farming (13-16). These studies have generally been small or case-control studies, and larger studies preferably with a cohort design are clearly warranted.

In this cohort study using information on parental occupation and cryptorchidism from nationwide registers in Denmark, we estimated the risk of cryptorchidism among sons with a mother or father working in horticulture or farming at the time of pregnancy compared to the risk among sons of parents in other occupations.

\section{Methods}

\section{Data sources}

Information on childbirths, hospital contacts, and employment status was obtained from national registers: the Danish Civil Registration System, the Danish National Patient Registry, the Fertility Database, and the Employment Classification Module from Statistics Denmark. The Danish Civil Registration System is a continuously updated demographic database that covers the entire Danish population (17). It was established on 1 April 1968 and, thereafter, all Danish inhabitants have been assigned a unique 10-digit identification number at birth. This register was used to identify children born in Denmark between 1980-2007. Children and parents were linked through the Fertility Database (18). The Danish National Patient Registry includes information about inpatient hospital contacts in Danish hospitals from 1 January 1977 onwards and outpatient hospital contacts from 1 January 1995 onwards (19) and was used to identify boys diagnosed with cryptorchidism. Since 1976, the Employment Classification Module has registered annual data on every citizen $\geq 15$ years old, who pays tax in Denmark according to economic and employment status (20). This module was used to extract information on parents' occupation in the relevant time period relative to child birth.

\section{Cohort}

The cohort included boys born in Denmark from 1 July 1980 to 31 December 2007 with one or both parents in active employment. We restricted our analyses to male infants of singleton pregnancies. For births in January through June, we applied the prior year's employment status while the current year's status was used for births in July through December. An active employment status indicated that the most important source of income for a person in a given year came from employment in the public or private sector.

\section{Exposure}

Exposed boys had at least one parent employed in farming or horticulture while unexposed boys had parents working in other occupations. To identify maternal and paternal occupation, we used occupational and industrial classification codes from the Employment Classification Module, Statistics Denmark. Occupations were coded according to the Danish Version of the International Standard Classification of Occupations for the years 1980-2007 and industries according to the Danish Industrial Codes for the years 1980-1992 and the Statistical Classification of Economic Activities in the European Community for the years 1993-2007. Horticultural workers and farmers were defined as selfemployed, skilled and unskilled workers and assisting spouses within the horticulture (excluding landscape gardeners) and farming industries. The category of other occupations did not include women or men who were unemployed, retired or students.

\section{Outcome}

Boys were followed for a hospital diagnosis of cryptorchidism recorded in the Danish National Patient Registry. The study included primary diagnoses of cryptorchidism with International Classification of Diseases (ICD) version 8 codes 75210, 75211, 75219 and ICD-10 codes Q53, Q531, Q532, and Q539.

\section{Statistical analysis}

Follow-up began at time of birth (in the period 1 July 1980 to 31 December 2007) and continued until a diagnosis of cryptorchidism, loss to follow-up (emigration, disappearance), death, or end of follow-up (31 December 2009), whichever came first.

We estimated hazard ratios (HR) and 95\% confidence intervals $(95 \% \mathrm{CI})$ using Cox regression to compare the occurrence of cryptorchidism among boys of mothers and fathers working as horticultural workers and farmers with boys of parents in other occupations. As an alternative analytic approach, we used logistic regression to estimate odds ratios (OR) and 95\% CI. Associations with maternal and paternal occupation were analyzed separately. Analyses were adjusted for birth year (1980-1989, 1990-1999, 2000-2007), maternal and paternal age $(<20,20-24$, $25-29,30-34, \geq 35$ years), maternal parity status $(0,1-2$, $\geq 3$ children) and geographical region at birth (the counties of Copenhagen, Frederiksborg, Roskilde, Western Zealand, Storstrøm, Bornholm, Funen, Southern Jutland, 
Ribe, Vejle, Ringkøbing, Aarhus, Viborg, Northern Jutland, and the combined municipalities of Copenhagen and Frederiksberg).

\section{Supplementary analyses}

We performed supplementary analyses to test the robustness of the main findings on maternal occupation and investigate possible associations more thoroughly. First, we compared the associations between maternal occupation and cryptorchidism in the more distant (1980-1992) and recent (1993-2007) birth period to see if possible associations between maternal occupation and cryptorchidism changed during the observation period. Second, we compared the risk among boys of women in the three occupational groups according to season of birth. Third, we estimated the risk among boys of women who did not work in farming or horticulture around the time of the birth but previously had worked in farming or horticulture at some point $2-5$ years before the birth. Fourth, we restricted the analysis to firstborns. Fifth, for the birth years 1992-2007, we analyzed data according to the importance of socioeconomic benefits in the 8-week period preceding pregnancy and in the first trimester of pregnancy (defined as gestational weeks 1-14). With these data, we were able to identify women who were likely present at work during or before pregnancy and women who were absent from work and received public benefit payments as a result of unemployment, education, sick leave, or maternity leave. We identified these women through the DREAM database (21), which includes information on all public transfer payments for Danish inhabitants on a weekly basis since 1991 . Finally, we repeated the analysis restricting it to boys with cryptorchidism who also had corrective surgery (orchiopexy). Boys with cryptorchidism and orchiopexy were identified by registry entries of codes 55600 , 55640 , KKFH00, KKFH01, or KKFH10 according to the Nordic Classification of Surgical Procedures codes.

All analyses were performed in SAS statistical software version 9.2 (SAS Institute, Cary, NC, USA).

\section{Results}

\section{Maternal occupation}

We identified 618081 boys born during 1980-2007 with a mother in active employment, including 2105 and 4520 boys born to maternal horticultural workers and farmers, respectively. The distribution of boys according to maternal occupation and number of previous childbirths, year of birth, and maternal and paternal age at birth is shown in table 1. Boys of maternal farm- ers generally had more older siblings, were to a larger extent born in the 1980s, and had parents of an older age than boys of maternal horticultural workers and boys of mothers in other occupations.

Within this cohort, 15740 (2.5\%) boys were diagnosed with cryptorchidism during follow-up from 1 July 1980 to 31 December 2009. Of these, 72 (3.4\%) and 157 (3.5\%) boys had a mother employed as horticultural worker or farmer, respectively, within the birth year if the birth occurred between July and December or the preceding year for births between January and June.

The median age at hospital diagnosis of cryptorchidism for the birth years from 1980-1989 was 8.1, 8.4, and 8.1 years for boys of mothers working in horticulture, farming, and other occupations, respectively. The respective median ages for the period 1990-1999 were 4.4, 5.1, and 5.1 years and 3.1, 3.1, and 2.3 for the birth years 2000-2007.

The adjusted HR for cryptorchidism showed an elevated but non-significantly increased risk among boys of maternal horticultural workers (HR 1.20, 95\% CI $0.95-1.52$ ) and a significantly increased risk among boys of maternal farmers (HR 1.31, 95\% CI 1.12-1.53) compared to boys of mothers in all other occupations (table 2). The alternative approach of analysing the data with logistic regression yielded similar results with an OR for cryptorchidism of 1.25 (95\% CI $0.98-1.58)$ for boys of maternal horticultural workers and $1.33(95 \%$ CI 1.13-1.56) for boys of maternal farmers.

\section{Birth-year periods}

The association between maternal occupation within horticulture and cryptorchidism was similar and nonsignificant in the two birth-year periods: 1980-1992 $(\mathrm{N}=38$, HR 1.16, 95\% CI 0.84-1.60) and 1993-2007 $(\mathrm{N}=34$, HR $1.28,95 \%$ CI $0.91-1.80)$. For boys of maternal farmers, the association with cryptorchidism was significantly increased for those born in the early period of 1980-1992 ( $\mathrm{N}=116$, HR $1.32,95 \%$ CI $1.10-1.59$ ) while, for boys born more recently, the association was slightly attenuated and no longer statistically significant ( $\mathrm{N}=41$, HR 1.24, 95\% CI 0.91-1.68).

\section{Season of birth}

An increased risk of cryptorchidism was found among boys of maternal horticultural workers born during the spring, autumn, and winter but not the summer. For sons of farmers, the risk was higher for births during the spring, summer, and autumn but not the winter (table 3 ). However, these variations were not large enough for an interaction between birth season and occupation on the risk of cryptorchidism (adjusted analysis, $\mathrm{P}=0.35$; chi ${ }^{2}$ test). 
Table 1. Distibution of male offspring according to maternal occupation and number of previous childbirths, year of birth, and maternal and paternal age at birth. No information on previous childbirths or paternal age at birth was available for $422(0.1 \%)$ and $6242(1 \%)$ boys, respectively.

\begin{tabular}{|c|c|c|c|c|c|c|}
\hline & \multicolumn{6}{|c|}{ Maternal occupation } \\
\hline & \multicolumn{2}{|c|}{ Horticulture } & \multicolumn{2}{|c|}{ Farming } & \multicolumn{2}{|c|}{ Other } \\
\hline & $\mathrm{N}$ & $\%$ & $\mathrm{~N}$ & $\%$ & $\mathrm{~N}$ & $\%$ \\
\hline \multicolumn{7}{|l|}{$\begin{array}{l}\text { Previous } \\
\text { childbirths }\end{array}$} \\
\hline 0 & 1062 & 50.5 & 968 & 21.4 & 283578 & 46.4 \\
\hline $1-2$ & 992 & 47.1 & 2834 & 62.7 & 312434 & 51.1 \\
\hline$\geq 3$ & 51 & 2.4 & 718 & 15.9 & 15022 & 2.5 \\
\hline \multicolumn{7}{|l|}{ Year of birth } \\
\hline 1980-1989 & 739 & 35.1 & 2299 & 50.9 & 206658 & 33.8 \\
\hline 1990-1999 & 981 & 46.6 & 1706 & 37.7 & 227110 & 37.1 \\
\hline 2000-2007 & 385 & 18.3 & 515 & 11.4 & 177688 & 29.1 \\
\hline \multicolumn{7}{|c|}{$\begin{array}{l}\text { Maternal age at } \\
\text { birth (years) }\end{array}$} \\
\hline$<20$ & 41 & 1.9 & 19 & 0.4 & 3334 & 0.5 \\
\hline $20-24$ & 579 & 27.5 & 437 & 9.7 & 83616 & 13.7 \\
\hline $25-29$ & 901 & 42.8 & 1359 & 30.1 & 230308 & 37.7 \\
\hline $30-34$ & 438 & 20.8 & 1689 & 37.4 & 205544 & 33.6 \\
\hline$\geq 35$ & 146 & 6.9 & 1016 & 22.5 & 88654 & 14.5 \\
\hline \multicolumn{7}{|c|}{$\begin{array}{l}\text { Paternal age at } \\
\text { birth (years) }\end{array}$} \\
\hline$<20$ & 9 & 0.4 & 4 & 0.1 & 784 & 0.1 \\
\hline $20-24$ & 279 & 13.4 & 126 & 2.8 & 37455 & 6.2 \\
\hline $25-29$ & 806 & 38.6 & 766 & 17.0 & 170730 & 28.2 \\
\hline $30-34$ & 622 & 29.8 & 1513 & 33.6 & 222986 & 36.8 \\
\hline$\geq 35$ & 372 & 17.8 & 2097 & 46.5 & 173290 & 28.6 \\
\hline
\end{tabular}

Table 2. Hazard ratios $(\mathrm{HR})^{\mathrm{a}}$ of cryptorchidism among boys born 1980-2007 according to parental occupation as horticultural worker, farmer, or in other occupations. [ $\mathrm{N}=$ number of boys; $95 \%$ $\mathrm{Cl}=95 \%$ confidence intervals.]

\begin{tabular}{lrrrr}
\hline & $\mathrm{N}$ & Events & $\mathrm{HR}$ & \multicolumn{1}{c}{$95 \% \mathrm{Cl}$} \\
\cline { 2 - 5 } Maternal occupation & & & & \\
$\quad$ Other & 611456 & 15511 & 1.00 & Ref \\
Horticulture & 2105 & 72 & 1.20 & $0.95-1.52$ \\
$\quad$ Farming & 4520 & 157 & 1.31 & $1.12-1.53$ \\
Paternal occupation & & & & \\
$\quad$ Other & 681778 & 17404 & 1.00 & Ref \\
$\quad$ Horticulture & 2157 & 74 & 1.20 & $0.96-1.51$ \\
Farming & 24348 & 671 & 1.04 & $0.96-1.12$ \\
\hline
\end{tabular}

a Adjusted for maternal and paternal age, number of previous childbirths, birth year and geographic region

\section{Previous employment as horticultural worker/farmer}

The risk was also assessed among boys of women with a previous - but not current - employment as a horticultural worker or farmer in the 2-5-year period before the childbirth. We identified 1327 and 1311 boys of mothers with a relevant prior employment as a horticultural worker or farmer, respectively. The risk of cryptorchidism was not increased among these boys compared to boys of mothers in other occupations (previous horticultural workers $\mathrm{N}=31$, HR $0.87,95 \%$ CI $0.61-1.23$; previous farmers $\mathrm{N}=38$, HR $1.12,95 \%$ CI $0.81-1.53$ ).

\section{First pregnancies}

When restricting to first pregnancies, we identified 1062 and 968 boys born to maternal horticultural workers and farmers, respectively. The HR for cryptorchidism was similar to those estimated in the overall analysis (horticultural workers $\mathrm{N}=38$, HR $1.21,95 \%$ CI $0.87-1.66$; farmers $\mathrm{N}=34$, HR $1.23,95 \%$ CI $0.88-1.73$ ).

\section{Socioeconomic benefits}

For births since 1992, we identified women likely to be at work and women not at work during the 8-week period preceding pregnancy and the first trimester of pregnancy. Sons of maternal horticultural workers and farmers who received no socioeconomic benefits (ie, they were likely to be at work) in the first trimester were of similar or slightly reduced risk compared to sons of other women who did not receive benefits (horticultural workers HR $0.68,95 \%$ CI $0.32-1.42$; farmers HR 1.03 , 95\% CI $0.70-1.52$ ). The same pattern was found for women who also likely worked in the 8 -week period preceding pregnancy (table $4 \mathrm{a}$ ).

Sons of maternal horticultural workers and farmers who received full socioeconomic benefits (ie, they were likely not working) in the first trimester seemed to be at increased risk compared to sons of women in other occupations who also received full benefits (horticultural workers HR 1.78, 95\% CI 0.56-5.65; farmers HR 1.97, $95 \%$ CI $0.72-5.40$ ). Sons of maternal horticultural workers and farmers who received partial benefits in the first trimester (at least one week) or who likely did not work in the 8-week period before pregnancy were at similarly increased risk compared to sons of women in other occupations who received the same benefits (table $4 \mathrm{~b}$ ). None of these associations reached levels of statistical significance as they were based on relatively few boys.

\section{Orchiopexy}

A proportion of $64 \%$ (10 125 boys) of cryptorchid boys also underwent surgery (orchiopexy). Of these, 51 and 111 were boys of mothers working in horticulture and farming, respectively, resulting in HR of 1.28 (95\% CI $0.97-1.68)$ and 1.29 (95\% CI 1.07-1.56), compared to orchiopexy among boys of mothers in other occupations.

\section{Paternal occupation}

For fathers in active employment, 708283 boys were identified and $18648(2.6 \%)$ were diagnosed with 
Table 3. Hazard ratios (HR) of cryptorchidism according to birth season ${ }^{\text {a }}$. [N=number of boys; $95 \% \mathrm{Cl}=95 \%$ confidence intervals.]

\begin{tabular}{|c|c|c|c|c|c|c|c|c|c|c|c|c|c|c|c|c|}
\hline \multirow[t]{3}{*}{ Occupation } & \multicolumn{16}{|c|}{ Birth season } \\
\hline & \multicolumn{4}{|c|}{ Spring a } & \multicolumn{4}{|c|}{ Summer b } & \multicolumn{4}{|c|}{ Autumn c } & \multicolumn{4}{|c|}{ Winter $^{\mathrm{d}}$} \\
\hline & $N$ & Events & $\mathrm{HR}$ & $95 \% \mathrm{Cl}$ & $\mathrm{N}$ & Events & $\mathrm{HR}$ & $95 \% \mathrm{Cl}$ & $\mathrm{N}$ & Events & $\mathrm{HR}$ & $95 \% \mathrm{Cl}$ & $\mathrm{N}$ & Events & $\mathrm{HR}$ & $95 \% \mathrm{Cl}$ \\
\hline Other & 162585 & 4154 & 1.00 & Ref & 158309 & 3948 & 1.00 & Ref & 148571 & 3751 & 1.00 & Ref & 141991 & 3658 & 1.00 & Ref \\
\hline Horticulture & 638 & 23 & 1.29 & $0.85-1.95$ & 497 & 11 & 0.81 & $.45-1.46$ & 431 & 15 & 1.21 & $0.73-2.01$ & 539 & 23 & 1.45 & $0.96-2.19$ \\
\hline Farming & 1155 & 41 & 1.32 & $0.97-1.80$ & 1198 & 38 & 1.22 & $.88-1.68$ & 1141 & 49 & 1.67 & $1.26-2.22$ & 1026 & 29 & 1.02 & $0.70-1.47$ \\
\hline
\end{tabular}

a Spring (March, April, May).

${ }^{\text {b }}$ Summer (June, July, August).

c Autumn (September, October, November).

${ }^{\mathrm{a}}$ Winter (December, January, February).

Table 4a. Hazard ratios (HR) a of cryptorchidism among boys of women who did not receive any socioeconomic benefit payments in the 8-week period preceding pregnancy and the first trimester. [ $\mathrm{N}=$ number of boys; $95 \% \mathrm{Cl}=95 \%$ confidence intervals.]

\begin{tabular}{|c|c|c|c|c|c|c|c|c|}
\hline \multirow[t]{2}{*}{ Occupation } & \multicolumn{4}{|c|}{$\begin{array}{c}\text { No benefits within } 8 \text { weeks before pregnancy and the first } \\
\text { trimester }\end{array}$} & \multicolumn{4}{|c|}{ No benefits in the first trimester } \\
\hline & $\mathrm{N}$ & Events & $\mathrm{HR}$ & $95 \% \mathrm{Cl}$ & $\mathrm{N}$ & Events & $\mathrm{HR}$ & $95 \% \mathrm{Cl}$ \\
\hline Other & 218913 & 4804 & 1.00 & Ref & 235112 & 5128 & 1.00 & Ref \\
\hline Horticulture & 360 & 7 & 0.78 & $0.37-1.64$ & 415 & 7 & 0.68 & $0.32-1.42$ \\
\hline Farming & 1104 & 26 & 1.08 & $0.73-1.59$ & 1167 & 26 & 1.03 & $0.70-1.52$ \\
\hline
\end{tabular}

${ }^{a}$ Adjusted for maternal and paternal age, number of previous childbirths, birth year and geographic region.

Table $\mathbf{4 b}$. Hazard ratios (HR) a of cryptorchidism according to socioeconomic benefit payments in the 8-week period preceding pregnancy and the first trimester. [ $\mathrm{N}=$ number of boys; $95 \% \mathrm{Cl}=95 \%$ confidence intervals.]

\begin{tabular}{|c|c|c|c|c|c|c|c|c|c|c|c|c|}
\hline \multirow[t]{2}{*}{ Occupation } & \multicolumn{4}{|c|}{ Full benefits for 8 weeks before pregnancy } & \multicolumn{4}{|c|}{ Partial benefits in the first trimester ${ }^{b}$} & \multicolumn{4}{|c|}{ Full benefits in the first trimester } \\
\hline & $\mathrm{N}$ & Events & $\mathrm{HR}$ & $95 \% \mathrm{Cl}$ & $\mathrm{N}$ & Events & HR & $95 \% \mathrm{Cl}$ & N & Events & $\mathrm{HR}$ & $95 \% \mathrm{Cl}$ \\
\hline Other & 21269 & 477 & 1.00 & Ref & 83672 & 1854 & 1.00 & Ref & 12921 & 292 & 1.00 & \\
\hline Horticultu & 73 & 3 & 1.49 & -4.66 & 577 & 24 & 1.45 & 2.19 & 59 & 3 & 1.78 & 5.65 \\
\hline Farming & 178 & 6 & 1.56 & $0.69-3.54$ & 316 & 12 & 1.72 & $0.97-3.05$ & 123 & 4 & 1.97 & $0.72-5.40$ \\
\hline
\end{tabular}

${ }^{a}$ Adjusted for maternal and paternal age, number of previous childbirths, birth year and geographic region.

${ }^{b}$ Partial benefits defined as $>1-<14$ weeks benefit payments in the first trimester (gestational weeks $1-14$ ).

cryptorchidism during follow-up. Fathers working in horticulture or farming had 2157 and 24348 sons, respectively, of whom $72(3.3 \%)$ and $742(3.0 \%)$ were diagnosed with cryptorchidism. Corresponding HR for cryptorchidism were 1.20 (95\% CI 0.96-1.51) for boys of paternal horticultural workers and 1.04 (95\% CI 0.96-1.12) for boys of paternal farmers (table 2).

\section{Discussion}

We studied the risk of cryptorchidism among boys born during a 28-year period spanning 1980-2007 and found slightly and similarly increased risks among boys of maternal horticultural workers and farmers suggesting a possible relationship with occupational exposure to pesticides. However, supplementary findings, for instance of an association with paternal horticultural workers and the general lack of association for women likely working in the first trimester, did not support the notion that this relationship is caused by pesticide exposure during pregnancy.

Previous Danish studies have looked into the possible relationship between pesticide exposure or parental work with likely exposure and the risk of cryptorchidism among sons. In a case-control study from 1998, Weidner et al (14) showed that sons of maternal gardeners born between 1983-1992 had a significantly 67\% higher risk of cryptorchidism than other boys while no associations were found for maternal farmers and paternal work. Similarly to the present cohort study, Weidner et al's study used diagnoses of cryptorchidism collected from the Danish National Patient Registry. However, comparing similar birth years we found a HR of 1.16 and were thus not able to identify an increased risk among boys of maternal horticultural workers born between 1980 1992. The number of sons with cryptorchidism of mater- 
nal gardeners was not precisely reported in the previous study, and further comparison with our study is thus not possible. Other Danish studies generally included relatively few cases of cryptorchidism and should therefore be interpreted with reservation. In 2011, Gabel et al (13) found a slightly but not significantly increased risk of cryptorchidism among sons of women exposed to pesticides in horticultural work. Also, Andersen et al (16) found a more than 3-fold higher prevalence of cryptorchidism among boys born to women working in greenhouses. Regarding pesticides, Damgaard et al (15) found higher levels of some pesticides in breast milk of mothers of cryptorchid sons than mothers of healthy sons (15). A large Norwegian study, found an overall reduced risk of cryptorchidism among farmers' sons. However, internally they observed that sons of farmers who were plausibly exposed to pesticides had an increased risk of cryptorchidism compared to sons of unexposed farmers (22). Outside Scandinavia, higher prevalences of cryptorchidism have been observed in areas of Italy with high pesticide use $(23,24)$. In contrast, a prospective study within the Danish National Birth Cohort found no relationship between cryptorchidism and maternal work as gardener or farmer (1).

At most, the results of the current study indicated a slightly increased risk among sons of mothers working in the horticulture and farming industries. Especially considering the supplementary findings, it seems plausible that this relationship is not directly related to pesticide exposure. First, we found a similarly increased risk of cryptorchidism among sons of paternal horticultural workers, although not statistically significant. While maternally mediated cryptorchidism among sons seems more likely, we cannot exclude the possibility that occupationally or environmentally derived paternal factors also play a role. However, for pesticide exposure to explain this relationship, it would require a similar endpoint no matter whether pesticides acted through different pathways among the mother and father, which seems implausible. Second, we found no association for those women most likely occupationally active during the first trimester, which includes the gestational period (weeks 8-14) suggested to represent the most sensitive time window for the development of the male reproductive tract (25). Finally, the proportion of female workers exposed to pesticides has been estimated to be approximately four times as high among horticultural workers as farmers (1), and our finding of a similar association with cryptorchidism for maternal farmers is thus a further indication that other factors may be more important than pesticide exposure for the observed association with cryptorchidism.

In Denmark, pregnant women are recommended to go on paid sick leave or change work tasks if harmful exposures are suspected in the workplace. Such initiatives are more common among pregnant horticultural workers than farmers or other workers in general (1). Women who actually go on sick leave may thus be those who normally experience the most harmful occupational exposures, which within the horticultural industry likely implies use of pesticides and chemical mixtures. We observed an elevated risk of cryptorchidism among sons of women who received benefit payments in the first trimester. This higher risk was found for women working in both horticulture and farming. Interestingly, we found a similarly increased risk among women on leave in the eight weeks preceding pregnancy and women fully absent from work in the first trimester. Albeit based on limited numbers, these particular findings support the view that the association with cryptorchidism is related to factors other than actual occupational exposures during pregnancy. Considering the short elimination half-lives of pesticides among humans, often $<24$ hours (26-29), it seems unlikely that pesticide exposure in the pre-pregnancy period should play an important role for the risk of cryptorchidism among sons of these women. Instead it appears that sons of women who are temporarily absent from an occupation in the farming and horticultural industries because of sickness leave, maternity leave, unemployment, or education have a higher risk of cryptorchidism. Furthermore, we would have expected that possible effects of occupational exposures during pregnancy on the overall association with cryptorchidism would have attenuated in the most recent years because of the increased focus on potential occupational hazards for pregnant workers - and we did not observe such a period effect.

Our study has some limitations that need attention. Transient cryptorchidism may never be clinically recognized and recorded in the Danish National Patient Registry because spontaneous descent is frequent during the first months of life. Furthermore, historically the register-based cumulative incidence of cryptorchidism in the Danish population continues to increase after the age of ten years $(30,31)$. Thus, our study of register-based recordings of cryptorchidism may likely underestimate mild and transient cases of cryptorchidism, especially among boys born in the most recent birth years with less follow-up time. Nevertheless, the observed prevalence of $2.5 \%$ of cryptorchidism in the cohort of boys of employed mothers resembles what has been reported in other studies (10-12). Furthermore, high positive predictive values have been found for the entries of a diagnosis of cryptorchidism (80\%) and orchiopexy (99\%) in the Danish National Patient Registry (32), and we found similar results when using the general cryptorchidism diagnosis and the more specific and severe orchiopexy definition. We used the Employment Classification Module provided by Statistics Denmark to determine each individual's affiliation to the Danish labor market. The Employment Classification Module includes information 
on the most important employment activity in terms of income throughout each year and, although this information has not been validated, the register is generally considered to be of high quality (20). Boys of maternal farmers were to a larger extent born in the early study period than boys of horticultural workers and mothers in other occupations. Boys of maternal farmers were thus, on average, followed to a higher age with any case of cryptorchidism more likely to be seen at a hospital. However, differences in length of follow-up between study groups were accounted for by the Cox regression model. This study was entirely register-based and specific individual exposures to pesticides were therefore not assessed. The application of chemicals in the farming and horticultural industries varies through season and fetuses expectedly have been exposed to different levels of pesticides and other chemicals depending on the time they were conceived. Still, we were not able to identify an interaction between season of birth and occupation on the association with cryptorchidism.

\section{Concluding remarks}

We observed a slightly increased risk of cryptorchidism among sons of maternal horticultural workers and farmers. Several supplemental findings failed to support the view that pesticide exposure during pregnancy causes this relationship. Specifically, we found (i) a similar association with paternal horticultural work, (ii) no association for women likely working in the most sensitive gestational weeks, (iii) a similar relationship for maternal horticultural workers as farmers, despite the fact that pesticide exposure is more prevalent in horticultural work, and (iv) a similar association for birth years early and late in the study period regardless of the increasing focus on avoiding potential occupational hazards for pregnant workers in more recent years. Still, because of this study's register-based nature, it is unresolved whether individual pregnant women with high pesticide exposure might present a substantial risk for cryptorchidism among sons.

\section{Acknowledgment}

This study is supported by grants from the Danish Working Environment Research Foundation (20080016458) to the MINERVA project and the Danish Research Council (10-082745). The authors are grateful to Michael V Christensen for expert management of the DREAM data and Harald Hannerz for merging data on children, parents, and occupations.

The authors declare no conflicts of interest.

\section{References:}

1. Zhu JL, Hjollund NH, Andersen AM, Olsen J. Occupational exposure to pesticides and pregnancy outcomes in gardeners and farmers: a study within the Danish National Birth Cohort. J Occup Environ Med. 2006;48(4):347-52. http://dx.doi. org/10.1097/01.jom.0000201566.42186.5f.

2. Hjollund NH, Bonde JP, Ernst E, Lindenberg S, Andersen AN, Olsen J. Pesticide exposure in male farmers and survival of in vitro fertilized pregnancies. Hum Reprod. 2004;19(6):1331-7. http://dx.doi.org/10.1093/humrep/deh203.

3. Thonneau P, Abell A, Larsen SB, Bonde JP, Joffe M, Clavert A et al. Effects of pesticide exposure on time to pregnancy: results of a multicenter study in France and Denmark. ASCLEPIOS Study Group. Am J Epidemiol. 1999;150(2):157-63. http:// dx.doi.org/10.1093/oxfordjournals.aje.a009975.

4. Andersen HR, Vinggaard AM, Rasmussen TH, Gjermandsen IM, Bonefeld-Jorgensen EC. Effects of currently used pesticides in assays for estrogenicity, androgenicity, and aromatase activity in vitro. Toxicol Appl Pharmacol. 2002;179(1):1-12. http://dx.doi.org/10.1006/taap.2001.9347.

5. Kojima H, Katsura E, Takeuchi S, Niiyama K, Kobayashi $\mathrm{K}$. Screening for estrogen and androgen receptor activities in 200 pesticides by in vitro reporter gene assays using Chinese hamster ovary cells. Environ Health Perspect. 2004;112(5):524-31. http://dx.doi.org/10.1289/ehp.6649.

6. Hass U, Boberg J, Christiansen S, Jacobsen PR, Vinggaard AM, Taxvig C et al. Adverse effects on sexual development in rat offspring after low dose exposure to a mixture of endocrine disrupting pesticides. Reprod Toxicol. 2012;34(2):261-74. http://dx.doi.org/10.1016/j.reprotox.2012.05.090.

7. Gray LE, Jr., Ostby J, Monosson E, Kelce WR. Environmental antiandrogens: low doses of the fungicide vinclozolin alter sexual differentiation of the male rat. Toxicol Ind Health. 1999;15(12):48-64. http://dx.doi.org/10.1191/074823399678846646.

8. Laier P, Metzdorff SB, Borch J, Hagen ML, Hass U, Christiansen $\mathrm{S}$ et al. Mechanisms of action underlying the antiandrogenic effects of the fungicide prochloraz. Toxicol Appl Pharmacol. 2006;213(2):160-71. http://dx.doi. org/10.1016/j.taap.2005.10.013.

9. Wolf C, Jr., Lambright C, Mann P, Price M, Cooper RL, Ostby $\mathrm{J}$ et al. Administration of potentially antiandrogenic pesticides (procymidone, linuron, iprodione, chlozolinate, p,p'-DDE, and ketoconazole) and toxic substances (dibutyl- and diethylhexyl phthalate, PCB 169, and ethane dimethane sulphonate) during sexual differentiation produces diverse profiles of reproductive malformations in the male rat. Toxicol Ind Health. 1999;15(12):94-118. http://dx.doi.org/10.1177/074823379901500109.

10. Ansell PE, Bull D, Chilvers CED, Coupland CAC, Pike MC. Cryptorchidism: a prospective study of 7500 consecutive male births, 1984-8. John Radcliffe Hospital Cryptorchidism Study Group. Arch Dis Child. 1992;67(7):892-9. http://dx.doi. org/10.1136/adc.67.7.892.

11. Berkowitz GS, Lapinski RH, Dolgin SE, Gazella JG, Bodian CA, Holzman IR. Prevalence and natural history of 
cryptorchidism. Pediatrics. 1993;92(1):44-9.

12. Boisen KA, Kaleva M, Main KM, Virtanen HE, Haavisto $\mathrm{AM}$, Schmidt IM et al. Difference in prevalence of congenital cryptorchidism in infants between two Nordic countries. Lancet. 2004;363(9417):1264-9. http://dx.doi.org/10.1016/ S0140-6736(04)15998-9.

13. Gabel P, Jensen MS, Andersen HR, Baelum J, Thulstrup AM, Bonde JP et al. The risk of cryptorchidism among sons of women working in horticulture in Denmark: a cohort study. Environ Health. 2011;10:100. http://dx.doi. org/10.1186/1476-069X-10-100.

14. Weidner IS, Moller H, Jensen TK, Skakkebaek NE. Cryptorchidism and hypospadias in sons of gardeners and farmers. Environ Health Perspect. 1998;106(12):793-6. http:// dx.doi.org/10.1289/ehp.98106793.

15. Damgaard IN, Skakkebaek NE, Toppari J, Virtanen HE, Shen H, Schramm KW et al. Persistent pesticides in human breast milk and cryptorchidism. Environ Health Perspect. 2006;114(7):1133-8. http://dx.doi.org/10.1289/ehp.8741.

16. Andersen HR, Schmidt IM, Grandjean P, Jensen TK, BudtzJorgensen E, Kjaerstad MB et al. Impaired reproductive development in sons of women occupationally exposed to pesticides during pregnancy. Environ Health Perspect. 2008;116(4):566-72. http://dx.doi.org/10.1289/ehp.10790.

17. Pedersen CB. The Danish Civil Registration System. Scand J Public Health. 2011;39(7 Suppl):22-5. http://dx.doi.org/10.1177/1403494810387965.

18. Blenstrup LT, Knudsen LB. Danish registers on aspects of reproduction. Scand J Public Health. 2011;39(7 Suppl):79-82. http://dx.doi.org/10.1177/1403494811399957.

19. Lynge E, Sandegaard JL, Rebolj M. The Danish National Patient Register. Scand J Public Health. 2011;39(7 Suppl):30-3. http://dx.doi.org/10.1177/1403494811401482.

20. Petersson F, Baadsgaard M, Thygesen LC. Danish registers on personal labour market affiliation. Scand J Public Health. 2011;39(7 Suppl):95-8. http://dx.doi. org/10.1177/1403494811408483.

21. Hjollund NH, Larsen FB, Andersen JH. Register-based followup of social benefits and other transfer payments: accuracy and degree of completeness in a Danish interdepartmental administrative database compared with a population-based survey. Scand J Public Health. 2007;35(5):497-502. http:// dx.doi.org/10.1080/14034940701271882.

22. Kristensen P, Irgens LM, Andersen A, Bye AS, Sundheim L. Birth defects among offspring of Norwegian farmers, 1967-1991. Epidemiology. 1997;8(5):537-44. http://dx.doi. org/10.1097/00001648-199709000-00011.

23. Garcia-Rodriguez J, Garcia-Martin M, Nogueras-Ocana M, de Dios Luna-del-Castillo, Espigares GM, Olea N et al.
Exposure to pesticides and cryptorchidism: geographical evidence of a possible association. Environ Health Perspect. 1996;104(10):1090-5.

24. Carbone P, Giordano F, Nori F, Mantovani A, Taruscio D, Lauria $\mathrm{L}$ et al. The possible role of endocrine disrupting chemicals in the aetiology of cryptorchidism and hypospadias: a population-based case-control study in rural Sicily. Int $\mathrm{J}$ Androl. 2007;30(1):3-13. http://dx.doi.org/10.1111/j.13652605.2006.00703.x.

25. Welsh M, Saunders PT, Fisken M, Scott HM, Hutchison GR, Smith LB et al. Identification in rats of a programming window for reproductive tract masculinization, disruption of which leads to hypospadias and cryptorchidism. J Clin Invest. 2008;118(4):1479-90. http://dx.doi.org/10.1172/JCI34241.

26. Barr DB, Angerer J. Potential uses of biomonitoring data: a case study using the organophosphorus pesticides chlorpyrifos and malathion. Environ Health Perspect. 2006;114(11):1763-9.

27. Leng G, Kuhn KH, Idel H. Biological monitoring of pyrethroids in blood and pyrethroid metabolites in urine: applications and limitations. Sci Total Environ. 1997;199(1-2):173-81. http:// dx.doi.org/10.1016/S0048-9697(97)05493-4.

28. Heredia-Ortiz R, Bouchard M. Toxicokinetic modeling of captan fungicide and its tetrahydrophthalimide biomarker of exposure in humans. Toxicol Lett. 2012;213(1):27-34. http:// dx.doi.org/10.1016/j.toxlet.2011.09.023.

29. Sams C, Jones K. Biological monitoring for exposure to deltamethrin: a human oral dosing study and background levels in the UK general population. Toxicol Lett. 2012;213(1):35-8. http://dx.doi.org/10.1016/j.toxlet.2011.04.014.

30. Jensen MS, Olsen LH, Thulstrup AM, Bonde JP, Olsen J, Henriksen TB. Age at cryptorchidism diagnosis and orchiopexy in Denmark: a population based study of 508,964 boys born from 1995 to 2009. J Urol. 2011;186(4 Suppl):1595-600. http://dx.doi.org/10.1016/j.juro.2011.03.070.

31. Morales-Suarez-Varela MM, Toft GV, Jensen MS, RamlauHansen C, Kaerlev L, Thulstrup AM et al. Parental occupational exposure to endocrine disrupting chemicals and male genital malformations: a study in the Danish National Birth Cohort study. Environ Health. 2011;10(1):3. http:// dx.doi.org/10.1186/1476-069X-10-3.

32. Jensen MS, Snerum TM, Olsen LH, Thulstrup AM, Bonde $\mathrm{JP}$, Olsen $\mathrm{J}$ et al. Accuracy of cryptorchidism diagnoses and corrective surgical treatment registration in the danish national patient registry. J Urol. 2012;188(4):1324-9. http://dx.doi. org/10.1016/j.juro.2012.06.045.

Received for publication: 25 March 2013 